\title{
APPLE LEAFCURLING MIDGE EGG LAYING ON DIFFERENT APPLE CULTIVARS AND ORCHARD PROPERTIES ON THE WAIMEA PLAINS, NELSON
}

\author{
J.T. SMITH and R.B. CHAPMAN \\ Dept. of Entomology and Animal Ecology, Lincoln University, Canterbury
}

\begin{abstract}
During the 1995-96 and 1996-97 growing seasons, regular monitoring of apple leafcurling midge (ALM) (Dasineura mali Diptera: Cecidomyiidae) egg laying was conducted in three conventionallymanaged orchard properties on the Waimea Plains, Nelson. The percentage of apple shoots infested with ALM eggs fluctuated considerably between seasons. The timing of egg laying peaks was similar between orchard properties, but differed between cultivars. Peakegg laying periods occurred 7-14 days earlier on 'Royal Gala' compared with 'Braeburn'. No notable difference in the level of apple shoot tips infested with ALM eggs occurred between cultivars. Similarly, no orchard property had consistently higher or lower levels of shoot tips infested with ALM eggs during the season. The importance of these findings for monitoring ALM is discussed briefly.
\end{abstract}

Keywords: apple leafcurling midge,Dasineura mali, egg laying, apple cultivar, monitoring

\section{INTRODUCTION}

Recent surveys of apple leafcurling midge (Dasineura mali Kieffer Diptera: Cecidomyiidae) (ALM) have shown it is now a serious pest in most apple growing regions of New Zealand (Tomkins et al. 1994; Smith and Chapman 1995a). The high incidence of ALM infestations in many commercial orchards clearly indicates the importance of this insect and has raised concern in the apple industry (Anon. 1994; June 1994; Smith and Chapman 1995a).

There are many problems associated with the control of ALM on apples (Foster $e t$ al. 1996). The ability to determine the most effective timing of insecticide sprays would improve the management of this species. Regular monitoring of shoot tips for ALM eggs is one method of providing such a guide. Presently, this involves the examination of 4050 shoots tips for the presence or absence of ALM eggs (Anon. 1995; Walkeret al. 1995; Anon. 1996). Even with such monitoring, suppression of ALM in orchards is still less than satisfactory. Very little scientific knowledge exists in New Zealand about the influence of locality within a district and modern apple cultivars on ALM phenology. Such information is necessary for successful long term pest management.

This paper reports on a study investigating the variability of ALM egg laying on apple cultivars and orchard properties in the Nelson district over two growing seasons.

\section{METHODS}

Three conventionally-managed orchards within a $10 \mathrm{~km}$ radius of each other on the Waimea Plains, Nelson, were used for the investigation from the end of September to April during 1995-96 and 1996-97 seasons. From each orchard, one block each of 'Braeburn' and 'Royal Gala' cultivar trees were selected. Each block consisted of approximately 750 trees.

Each week 50 apple shoot tips, which were actively growing and approximately vertical, were haphazardly sampled from each block. Each tip was examined using a hand lens for the presence of freshly laid ALM eggs.

Data on the levels of shoot tip infestation between seasons, orchards and cultivars

Proc. 50th N.Z. Plant Protection Conf. 1997: 247-251 
were presented graphically and trends in the timing and level of peak periods of shoot egg infestation were compared.

\section{Seasonal variation}

\section{RESULTS}

The number of egg laying peaks for the 1995-96 season was distinctly different from that of the following season (Fig. 1). Five peaks occurred during the 1995-96 season whereas in the 1996-97 season, only four peaks occurred, assuming that the slight increased infestation during the beginning of October 1996-97 represents the first peak. The mean percentage of shoot tips infested with ALM eggs between the 1995-96 and 1996-97 seasons fluctuated considerably (Fig. 1). The two highest levels of egg infestation recorded for the 1995-96 season were $18 \%$ and $24 \%$ compared with $25 \%$ and $44 \%$ for the $1996-97$ season. In the 1995-96 season, ALM eggs were absent from shoots only from 1 to 11 November 1995. However, in the 1996-97 season, ALM eggs were absent from shoots on three occasions: 14 October to 11 November 1996, 13 January, and 17 February 1997 (Fig. 1).

\section{Cultivar variation}

The percentage of shoot tips infested with ALM eggs during the season was similar for 'Braeburn' and 'Royal Gala' apple cultivars (Fig. 1). In each of the first three egg laying peaks, the difference between cultivars was less than $3 \%$ shoot tip infestation. The last peak period was the exception, with 'Royal Gala' recording twice the percentage of shoot tips infested compared with that of 'Braeburn' (Fig. 1). A distinct difference in the timing of peak egg infestation of shoot tips occurred between apple cultivars during the seasons. The timing of the peak egg laying period occurred an average of 7-14 days earlier on 'Royal Gala' than on 'Braeburn' (Fig. 1).

\section{Locality variation}

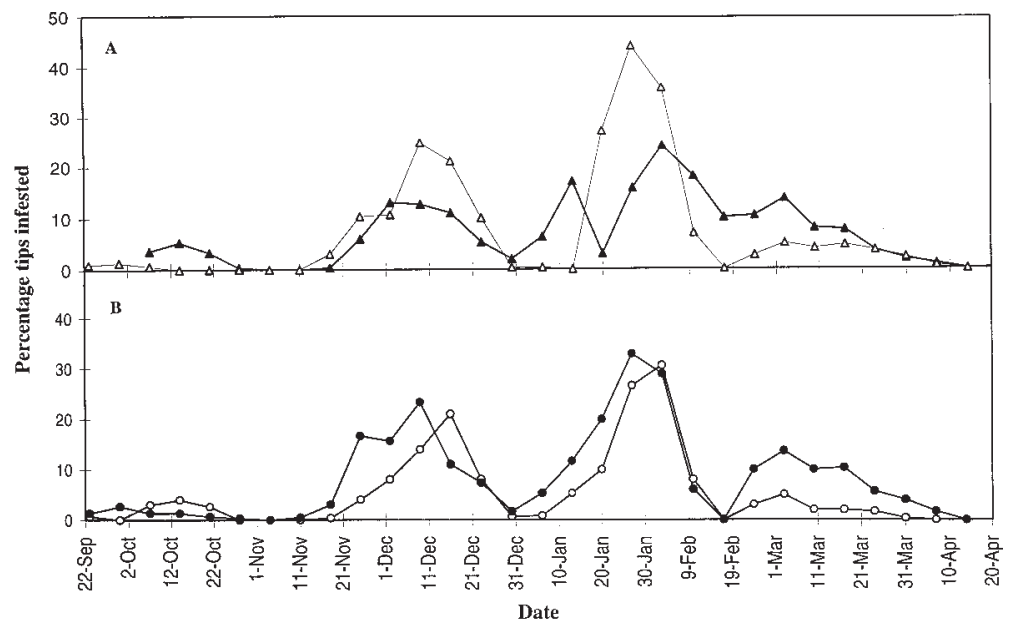

FIGURE 1: Mean weekly percentage of shoot tips infested with apple leafcurling midge eggs on the Waimea Plains, Nelson. A. During the 1995-96 $(-s-)$ and 1996-97 ( $\square-$ ) seasons (average of two cultivars and three orchard properties). B. Between 'Braeburn' ( $-m)$ and 'Royal Gala' ( — - ) apple cultivars (average of two seasons and three properties). 
At each property, an average of four egg-laying peaks were recorded during each season (Fig. 2). These peaks generally occurred during mid October, mid December, end of January and the beginning of March. The proportion of tips infested with freshly laid ALM eggs varied considerably during a season. The greatest number of eggs were recorded during the end of January (Fig. 2). Property 2 had the lowest level of infestation, with $25 \%$ of shoot tips infested with ALM eggs compared with properties 1 and 3 which had $50 \%$ and $69 \%$ of tips infested with ALM eggs respectively.

\section{DISCUSSION}

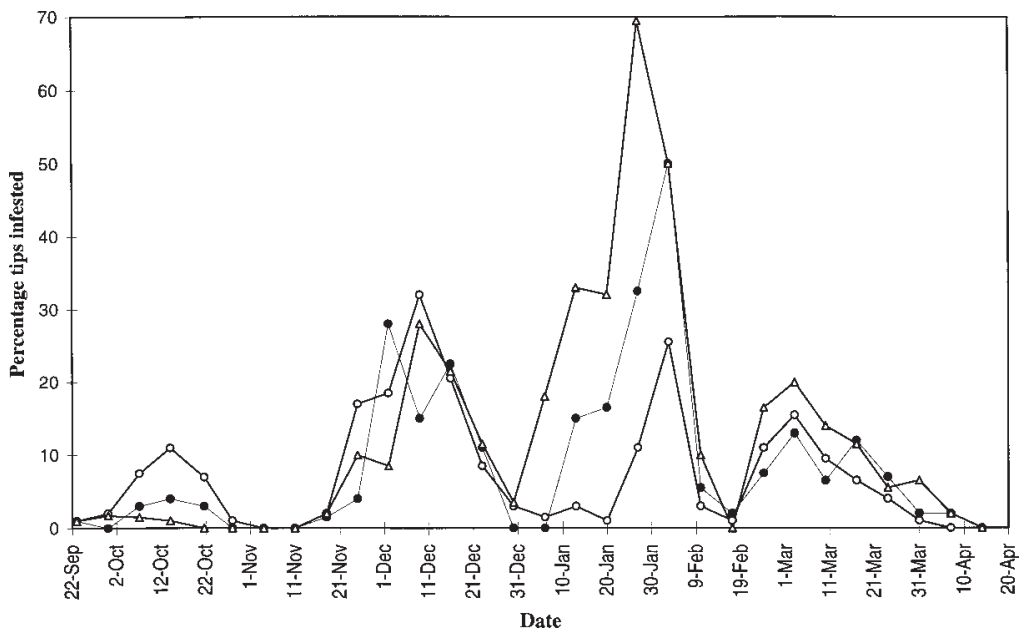

FIGURE 2: Mean weekly percentage of shoot tips infested with apple leaf curling midge eggs at three orchard properties $\left(1, \uparrow ; 2, \frac{\mathrm{m}}{\longrightarrow}\right.$; $3,-\square_{-}$) on the Waimea Plains, Nelson (average of two seasons and two cultivars).

Based on the series of peaks observed in the percentage of shoot tips infested with eggs, four generations of ALM were indicated in the Nelson district during the 1996-97 season. The same number of generations were also recorded in Nelson during the 199495 season (Walker et al. 1995).

Overwintering ALM could have emerged earlier in the 1996-97 season than in the 1995-96 season and this may account for the early low levels of shoot tip infestation. Todd (1959) suggested that the reason for low severity of attack by ALM early in the 1955-56 season was that only early leafing varieties of apples were available for infestation. Later in the season, abundant oviposition sites were available and may have resulted in heavier infestations. The fact that fewer ALM adults would be present, earlier in the season, is also likely to be an important factor contributing to lower levels of ALM infestation early in the season.

Little overlapping of generations occurred in the 1996-97 season with egg laying periods being recorded in distinctive peaks, followed by periods where no ALM eggs were present. In comparison, ALM eggs were recorded on shoot tips throughout most of the 1995-96 season. This would have resulted in the majority of adults emerging at a similar time for the second and third generations of ALM, therefore resulting in a higher incidence of shoot tip infestation in the 1996-97 season. However, the effect of weather conditions between the two seasons needs to be considered as this may help explain why the level of egg infestation of tips in the 1996-97 season was double that of the previous season.

The results from this investigation suggest both 'Braeburn' and 'Royal Gala' apple 
cultivars are similarly prone to ALM oviposition, as measured by the percentage of shoot tips with eggs during the season. None of the 12 apple cultivars Todd (1959) studied were more or less prone to ALM attack, although neither 'Braeburn' or 'Royal Gala' were tested. Nevertheless, in this study data are based on the presence of ALM eggs and not on their survival or resulting leaf damage. Further studies into these factors may reveal a difference in the susceptibility of cultivars to ALM attack.

The differences that exist between apple cultivars, with respect to the timing of egg laying peaks, is most likely to be due to the phenology of the individual apple cultivars. 'Royal Gala' is an early maturing variety and hence begins bud break and shoot extension earlier than that of 'Braeburn'. Since ALM is more likely to oviposit on shoots which are actively growing (Smith and Chapman 1995b), those varieties that show these characteristics during emergence of adult ALM would be more likely to be infested. As the season progresses, the difference between growth phases of apple cultivars would become less apparent and hence the recording of the timing of peak periods of egg laying during March was identical for both 'Royal Gala' and 'Braeburn'.

It would appear that locality within a district is not a major influence on the timing of peak periods of ALM egg laying (Fig. 2). However, although the peaks of ALM egg laying over the season are similar for each property, two important points need to be considered. First, the data represented in Fig. 2 are an average of two seasons. A greater variation between properties often occurs within a single season. Secondly, a slight difference in the timing of egg laying, such as a week, between properties, is still important. This is especially true if orchardists want to achieve the greatest effect from their insecticide applications and highlights the need to monitor ALM populations in an individual orchard and not rely on district trends.

The variation in the level of ALM shoot tip infestation between properties is most likely attributed to individual orchard management practices, since no property was consistently higher or lower than another. Further investigation into such practices and management is required to ascertain possible explanation for the level of infestation differences recorded in this study.

Overall this investigation has further highlighted the need for individual orchardists to monitor their own properties and even cultivars early in the growing season to achieve the most effective timing of control measures for ALM.

\section{ACKNOWLEDGEMENTS}

The financial support provided by ENZA New Zealand (International) is gratefully acknowledged. We would also like to thank the orchardists involved in this study for their cooperation and use of their properties.

\section{REFERENCES}

Anon., 1994. Apple leafcurling midge, monitoring and control. Pipmark Technical Bulletin 4 October. ENZA New Zealand (International) Wellington. 4pp.

Anon., 1995. Apple leafcurling midge Pipmark Technical Bulletin 6 October. ENZA New Zealand (International) Wellington. 4pp.

Anonymous, 1996. New Zealand Integrated Fruit Production - Pipfruit Manual. ENZA New Zealand (International) Wellington.

Foster, S.P., Harris, M.O. and Dhana, S., 1996. Identification of the sex pheromone of the apple leafcurling midge. Hort Research Report, PI95/40, for ENZA New Zealand (International). 8pp.

June, S., 1994. Pipfruit industry's concern with the increased incidence of apple leaf curling midge. Internal ENZA (International) Report: 5pp.

Smith, J.T. and Chapman, R.B., 1995a. A survey of apple leafcurling midge (Dasyneura mail) in the Nelson district. Proc. 48th N.Z. Plant Prot. Conf: : 117-120.

Smith, J.T. and Chapman, R.B., 1995b. Apple Leafcurling Midge Population Studies. A report for ENZA New Zealand (International). 27pp

Todd, D.H., 1959. The apple leafcurling midge Dasyneura mali Kieffer, seasonal history, varietal susceptibility and parasitism 1955-58. N.Z. J. Agric. Res. 2: 859-869.

Tomkins, A.R., Wilson, D.J., Hutchings, S.O. and June, S., 1994. A survey of apple 
leafcurling midge (Dasyneura mali) management in Waikato orchards.Proc. 47th N.Z. Plant Prot. Conf:: 346-349.

Walker, J.T.S., Shaw, P.W., White, V. and Bohm, V.F., 1995. The phenology of apple leafcurling midge in Hawkes Bay and Nelson orchards. Hort Research Report, HR95/197, for ENZA New Zealand (International). 13pp. 